\title{
Regulation of a hair follicle keratin intermediate filament gene promoter
}

\author{
S. M. Dunn*, R. A. Keough‡, G. E. Rogers and B. C. Powell§ \\ Department of Animal Science, University of Adelaide, Waite Campus, Glen Osmond, South Australia 5064, Australia \\ *Author for correspondence \\ ¥Present address: Hanson Centre for Cancer Research, Institute of Medical and Veterinary Science, Frome Road, Adelaide, South Australia 5000, Australia \\ §Present address: Child Health Research Institute, Women's and Children's Hospital, 72 King William Street, North Adelaide, South Australia 5006, Australia
}

Accepted 6 October; published on WWW 12 November 1998

\section{SUMMARY}

During hair growth, cortical cells emerging from the proliferative follicle bulb rapidly undergo a differentiation program and synthesise large amounts of hair keratin proteins. To identify some of the controls that specify expression of hair genes we have defined the minimal promoter of the wool keratin intermediate filament gene $K 2.10$. The region of this gene spanning nucleotides -350 to +53 was sufficient to direct expression of the lac $Z$ gene to the follicle cortex of transgenic mice but deletion of nucleotides -350 to -150 led to a complete loss of promoter activity. When a four base substitution mutation was introduced into the minimal functional promoter at the binding site for lymphoid enhancer factor 1 (LEF-1), promoter activity in transgenic mice was decreased but specificity was not affected. To investigate the interaction of trans-acting factors within the minimal $K 2.10$ promoter we performed DNase I footprinting analyses and electrophoretic mobility shift assays. In addition to LEF-1, Sp1, AP2-like and NF1-like proteins bound to the promoter. The Sp1 and AP2-like proteins bound sequences flanking the LEF-1 binding site whereas the NF1-like proteins bound closer to the transcription start site. We conclude that the LEF-1 binding site is an enhancer element of the $K 2.10$ promoter in the hair follicle cortex and that factors other than LEF-1 regulate promoter tissueand differentiation-specificity.

Key words: Hair follicle, Keratin, Transcription factor, LEF-1

\section{INTRODUCTION}

The hair follicle is a specialised epithelial structure derived from the epidermis. It is composed of several different cell types which form the medulla, cortex and outer cuticle of the hair shaft and the surrounding inner and outer root sheaths. Differentiation of cells emerging from the follicle bulb to form the hair involves the coordinated activation of many hair structural genes (for review see Powell and Rogers, 1997). The major proteins synthesised in the hair shaft are the keratin intermediate filament (IF) and keratin-associated proteins (KAP). Keratin IF are composed of type I and type II proteins which are co-expressed in specific pairs to form 8-10 nm diameter heteropolymeric filaments (Steinert and Roop, 1988). At least four different pairs of hair keratin IF are expressed in the follicle cortex and the genes are activated sequentially, early in hair shaft formation (Kaytes et al., 1991; Powell et al., 1992; Tobiasch et al., 1992; Winter et al., 1994; Rogers et al., $1996,1997)$. The focus of this study, the type II IF gene $K 2.10$, is first expressed in differentiating cortical keratinocytes of the lower shaft (Powell et al., 1992). The KAP proteins which form a matrix between the filaments comprise several families whose genes are activated after the IF genes (for review see Powell and Rogers, 1997).

The intricate pattern of hair keratin gene expression during cortical cell differentiation suggests that the timing and location of transcriptional activation are precisely controlled. Little is known about how this is achieved. Is there a folliclespecific transcription factor which acts as a master switch for all hair keratin genes, or does transcription of each gene occur independently, utilising various combinations of widely expressed factors? The latter scenario has been suggested for regulation of several epidermal keratin IF genes (for review see Eckert et al., 1997). Binding sites for AP1, AP2, Sp1, POU factors and other common transcription factors, sometimes found in clusters in regulatory elements, are important for expression of many epidermal keratin IF genes.

Consensus AP1 and AP2 binding sites occur in the promoters of several hair keratin genes and sequence comparisons have identified other putative regulatory motifs (McNab et al., 1989; Kaytes et al., 1991; Powell et al., 1991, 1992). One prominent motif, originally termed HK-1 (Powell et al., 1991), is now recognised as a binding site for lymphoid enhancer factor 1 (LEF-1) (Zhou et al., 1995). LEF-1 was first identified as a pre$\mathrm{B}$ and $\mathrm{T}$ cell protein with a DNA-binding domain homologous to that of high mobility group proteins, and is related to $\mathrm{T}$ cell factor 1 (TCF-1) (Travis et al., 1991; Waterman et al., 1991). LEF-1/TCF-1 binding sites are found in a number of T cellspecific enhancers, including those of the $\mathrm{T}$ cell receptor (TCR)$\alpha,-\beta$ and $-\delta$ genes, the CD3, CD 4 and adenosine deaminase genes and HIV-1 (Gottschalk and Leiden, 1990; Redondo et al., 1990; Sawada and Littman, 1991; Haynes et al., 1996). LEF-1 
has an essential role in TCR- $\alpha$ and HIV-1 enhancer activation in which it acts synergistically with other transcription factors (Giese et al., 1995; Sheridan et al., 1995).

The perceived biological roles of LEF-1 expanded when it was shown to be expressed widely during embryogenesis (Oosterwegel et al., 1993). Functional studies using targeted gene inactivation and ectopic expression indicate that LEF-1 plays an essential part in hair follicle morphogenesis (van Genderen et al., 1994; Zhou et al., 1995; Kratochwil et al., 1996). In mutant mice deficient in LEF-1, follicle development is initiated at the normal stage but is arrested shortly thereafter and the mice are hairless (van Genderen et al., 1994). During follicle morphogenesis and hair growth, LEF-1 is expressed in several locations, notably the embryonic ectoderm, the ectodermal cells at the leading edge of the follicle placode, the follicle bulb and lower shaft of adult follicles and the dermal papilla (Zhou et al., 1995). The finding of conserved LEF-1 binding motifs in the promoters of many hair keratin genes (Powell et al., 1991; Zhou et al., 1995; Rogers et al., 1996) implies a central role for this factor in hair keratin gene transcription in the terminal stages of hair growth.

To investigate promoter function of hair keratin genes it is necessary to use transgenic mice because of the lack of a cell culture system. Preliminary studies of two hair keratin promoters have been undertaken in transgenic mice, the sheep K2.10 promoter (Powell and Rogers, 1990; Keough et al., 1995) and a mouse KAP gene promoter (McNab et al., 1990). In both cases, transgene specificity mimicked that of the endogenous gene.

We have shown previously that $2.8 \mathrm{~kb}$ of the sheep $K 2.10$ promoter is sufficient to drive correct expression of the SV40 $\mathrm{T}$ antigen (TAg) in the follicle cortex of transgenic mice (Keough et al., 1995). Here we have used mouse transgenesis to test smaller fragments of the proximal promoter of the sheep $K 2.10$ gene for activity and we show that $400 \mathrm{bp}$ of promoter is able to function as a hair cortex-specific promoter. Using in vitro techniques we show that transcription factors from the Sp1, AP2 and NF1 families are capable of binding to this promoter. LEF-1 also binds the $K 2.10$ promoter and we show that the 400 bp promoter is reduced in activity when the LEF1 binding site is mutated. We postulate that LEF-1 acts as a general enhancer of $K 2.10$ transcription, possibly by coordinating interactions between flanking transcription factors, thus adding a further dimension to the function of LEF1 in hair development.

\section{MATERIALS AND METHODS}

\section{Construction of $\mathrm{K2.10}$-lacZ fusion genes}

The transgenes were generated from a $K 2.10$ promoter construct containing an engineered SalI site in the $5^{\prime}$ untranslated region at position +53 (Keough et al., 1995). The HindIII/BamHI lacZ fragment $(3.85 \mathrm{~kb})$ from pCH110 (Pharmacia) was cloned into this site. The K2.10(400)-lacZ transgene was isolated by ApaI digestion and contained approximately 400 bp of $K 2.10$ proximal promoter from nucleotide -350 to +53 . K2.10(400 $L E E F-1)$-lacZ was generated by site-directed mutagenesis of the LEF-1 binding site at position -185 in K2.10(400)-lacZ using the oligonucleotide 5'TCAGGCCTGTTTCATCCTAGACGCCGTTTACGAGCTTC-3'. The transgene fragment was isolated using ApaI as above. K2.10(400)lacZ and $K 2.10(400 \Delta L E F-1)$-lacZ contained approximately $200 \mathrm{bp}$ of
$K 2.10$ exon 1 sequence at the $3^{\prime}$ end of the lac $Z$ fragment. The $K 2.10$ (200)-lacZ transgene contained 200 bp of $K 2.10$ proximal promoter from the HincII site at position -149 to the SalI site at +53 but did not contain the $K 2.10$ exon 1 sequence.

\section{Production of transgenic mice and $\beta$-galactosidase histochemistry}

Transgenes were microinjected into fertilised mouse oocytes essentially as described by Hogan et al. (1986) and transgenic mice were detected by Southern blot analysis with a $3.85 \mathrm{~kb}$ lacZ probe.

Mouse dorsal skin containing hair follicles in anagen phase was embedded in OCT compound. Cryostat sections $(14 \mu \mathrm{m})$ were airdried and fixed in $0.2 \%$ glutaraldehyde for 2 minutes. $\beta$-Galactosidase activity was detected by the conversion of 5-bromo-4-chloro-3indolyl- $\beta$-D-galactopyranoside (X-gal) to blue stain (Sanes et al., 1986). Sections were counterstained with eosin and mounted in Gurr's Depex mounting medium.

\section{Preparation of nuclear extracts}

Hair (or wool) follicles were isolated from the skins of 10-15 two to four day old Swiss mice (or from fetal sheep between days 100 and 140 of gestation) using trypsin and collagenase digestion (Rogers et al., 1987). Extracts from sheep and mouse follicles produced the same results in DNA binding experiments and were used interchangeably. Washed, pelleted follicles were resuspended in $10 \mathrm{mM}$ Hepes, $\mathrm{pH}$ 7.9, $10 \mathrm{mM} \mathrm{KCl}, 0.1 \mathrm{mM}$ EDTA, $0.1 \mathrm{mM}$ EGTA, $1 \mathrm{mM}$ DTT, $0.5 \mathrm{mM}$ PMSF, $0.6 \%$ NP40 and cells were lysed in a Dounce homogeniser. Nuclei were pelleted, then extracted in $300-500 \mu \mathrm{l}$ of $10 \mathrm{mM}$ Hepes, $\mathrm{pH} 7.9,0.1 \mathrm{mM}$ EDTA, $0.1 \mathrm{mM}$ EGTA, $1.5 \mathrm{mM} \mathrm{MgCl}_{2}, 400 \mathrm{mM}$ $\mathrm{KCl}, 25 \%$ (v/v) glycerol, $0.5 \mathrm{mM}$ DTT, $0.5 \mathrm{mM}$ PMSF and incubated on ice for 20 minutes. Debris was pelleted by centrifugation for 10 minutes at $15,000 \mathrm{~g}$ at $4{ }^{\circ} \mathrm{C}$. The supernatant was collected and aliquots of the nuclear extract were snap frozen and stored at $-70^{\circ} \mathrm{C}$. Recombinant human AP2 was purchased (Promega).

\section{Electrophoretic mobility shift assay (EMSA)}

Electrophoretic mobility shift assays (EMSA) were performed essentially as described by Schneider et al. (1986). Binding reactions contained 5-6 $\mu \mathrm{g}$ of follicle nuclear extract and $0.2 \mathrm{ng}$ of ${ }^{32} \mathrm{P}-$ labelled, double-stranded oligonucleotide probe in a final volume of 15-20 $\mu$, which included $20 \mathrm{mM}$ Tris-HCl, $\mathrm{pH} 8,1 \mathrm{mM}$ EDTA, $5 \mathrm{mM}$ DTT, $50 \mathrm{mM} \mathrm{KCl}, 0.5 \mu \mathrm{g}$ polydIdC (Boehringer Mannheim) and 10\% (v/v) glycerol. Unlabelled competitor DNA (at 100-fold molar excess over probe) was added prior to probe addition where indicated. Reactions were incubated at room temperature for 20 minutes. The $K 2.10$ probe sequences are shown in Fig. 3 and the $\triangle \mathrm{LEF}-1$ probe was $5^{\prime}$-AACGGCGTCTAGGATGAAAC-3'. The non-specific oligonucleotide was 5'-TGGCTCAGGAGGAAGATCCGC-3'. Probes used as canonical binding sites for transcription factors were: Sp1 (Briggs et al., 1986) 5'-ATTCGATCGGGGCGGGGCGAGC-3'; NF1 (Leegwater et al., 1985) 5'-TTTTGGATTGAAGCCAATATGATAA3'; AP2 (Williams et al., 1988) 5'-GATCGAACTGACCGCCCGCGGCCCGT-3'. Where antibodies were included, $1 \mu \mathrm{l}$ of rabbit polyclonal antiserum was incubated with the mixture minus probe for 30 minutes on ice, the probe was then added and incubation continued for 20 minutes at room temperature. Antiserum against $\mathrm{CTF} / \mathrm{NF} 1$ proteins was a gift from Dr N. Tanese (New York University Medical Center) and LEF-1 antiserum was a gift from Dr R. Grosschedl (University of California, San Francisco). Affinitypurified rabbit antibodies to Sp1 were purchased from Santa Cruz Biotech. Reactions were electrophoresed at $150 \mathrm{~V}$ on $6 \%$ polyacrylamide gels buffered by $50 \mathrm{mM}$ Tris $\mathrm{HCl}, \mathrm{pH} 8.5,380 \mathrm{mM}$ glycine, 2 mM EDTA and dried gels were autoradiographed for 12 to 72 hours.

\section{DNase I footprinting}

DNase I footprinting was performed with modifications of a described 
procedure (Jerkins et al., 1995). Probes of 150 to $300 \mathrm{bp}$ were generated by PCR using a plasmid template containing the $K 2.10$ promoter. One PCR primer was end-labelled using $\left[\gamma_{-}{ }^{32} \mathrm{P}\right] \mathrm{ATP}$ and T4 polynucleotide kinase. The same ${ }^{32} \mathrm{P}$-labelled primer was used in dideoxynucleotide chain termination sequencing reactions, which were electrophoresed in parallel with the footprint reactions to locate footprint positions. DNA binding reactions containing $50 \mu \mathrm{g}$ of crude nuclear extract (or $30 \mathrm{ng}$ of recombinant AP2 protein), $50 \mathrm{mM} \mathrm{KCl}$, $20 \mathrm{mM}$ Tris- $\mathrm{HCl}, \mathrm{pH} 8,1 \mathrm{mM}$ EDTA, $1 \mathrm{mM}$ DTT, $10 \%$ glycerol, 1.5 $\mu \mathrm{g}$ polydIdC and $2 \mathrm{ng}$ of probe in a final volume of $50 \mu \mathrm{l}$ were incubated on ice for 10 minutes then at room temperature for a further 10 minutes. $50 \mu \mathrm{l}$ of $5 \mathrm{mM} \mathrm{CaCl}_{2}, 10 \mathrm{mM} \mathrm{MgCl}_{2}$ were added to the mixture and incubation was continued for 5 minutes at room temperature. DNase I (Worthington Biochemical Corporation) was added to a concentration of between 0.2 and 2 units $/ \mathrm{ml}$ and allowed to digest for 30 seconds at room temperature. Digestion was stopped by the addition of $90 \mu \mathrm{l}$ of $30 \mathrm{mM}$ EDTA, $200 \mathrm{mM} \mathrm{NaCl}, 1 \%$ SDS and $100 \mu \mathrm{g} / \mathrm{ml}$ yeast RNA, samples were extracted with phenol/chloroform, ethanol precipitated, then resuspended in formamide load solution. DNA was separated on $6 \%$ polyacrylamide, $8 \mathrm{M}$ urea sequencing gels, which were then dried and autoradiographed.

\section{RESULTS}

\section{Functional mapping of the $\mathbf{K} \mathbf{2 . 1 0}$ promoter}

We have previously shown that $2.8 \mathrm{~kb}$ of sheep K2.10 $5^{\prime}$ promoter sequence directs expression to the hair follicle cortex in transgenic mice (Powell and Rogers, 1990; Keough et al., 1995). To further define the minimal functional $K 2.10$ promoter, a K2.10(400)-lacZ transgene was constructed, containing $400 \mathrm{bp}$ of proximal $K 2.10$ promoter $(-350$ to +53$)$ linked to the E. coli lac $Z$ reporter gene (Fig. 1). Twelve founder (G0) transgenic mice were generated with between 1 and 200 copies of the transgene per genome (data not shown). Only four mice expressed the transgene as determined by $\beta$-galactosidase activity (Fig. 2A). Expression was confined to the cortex of the hair follicle in each case and was usually seen over the entire cortex, while no expression was detected elsewhere in the skin. Transgene expression was not copy number-dependent, as the greatest intensity of $\beta$-galactosidase staining was observed in a mouse with a low transgene copy number, while some of the non-expressing animals carried a large number of transgenes (data not shown).

A second deletion construct, K2.10(200)-lacZ, containing the proximal 200 bp of the $K 2.10$ promoter $(-149$ to +53$)$ linked to lacZ (Fig. 1) was then analysed. Seventeen G0 K2.10(200)-lacZ transgenic mice were generated, with transgene copy numbers ranging from 5 to 100 copies. No $\beta$-galactosidase activity was detectable in the hair follicles or skin of these mice (data not shown), indicating that sequences outside the 200 bp proximal promoter are required for expression.

To investigate the role of the highly conserved LEF-1 motif (HK-1: Powell et al., 1991; Zhou et al., 1995), the $K 2.10(400 \Delta L E F-1)$-lacZ construct (Fig. 1) was generated by site-directed mutagenesis of this element in K2.10(400)-lacZ. The LEF-1 binding site at -185 was mutated from $5^{\prime}$-CTTTGAAG- $3^{\prime}$ to 5'-CGTCTAGG-3', a mutation which abolished protein binding (see later, Fig. 4B). Thirteen G0 K2.10(400 LLEF-1)lac $Z$ transgenic mice were produced with copy numbers ranging from approximately 10 to 100 copies. Two transgenic mice showed a low level of $\beta$-galactosidase activity in the hair follicle cortex (Fig. 2B,C). Unlike K2.10(400)-lacZ mice, expression in the $K 2.10(400 \Delta L E F-1)$-lacZ animals was patchy and only a few cortical cells were stained. Additionally, both mice showed expression in only $1-10 \%$ of pelage follicles. Thus, mutation of the LEF-1 site appeared to reduce the level of hair keratin gene expression, but did not affect cell type specificity.

\section{Nuclear proteins bind adjacent LEF-1 and AP2 sites in the $\mathbf{K} \mathbf{2 . 1 0}$ promoter}

Having ascertained that the $K 2.10400 \mathrm{bp}$ promoter contained the sequence information required for follicle cortex-specific expression, we attempted to identify nuclear proteins in the follicle which specifically bound sequences within this promoter. An impediment to studying hair keratin gene regulation is the difficulty in preparing purified cell populations which express the appropriate keratin genes. The whole follicle nuclear extracts used here to analyse DNA-binding proteins were crude preparations containing other follicle cell types in addition to the cortical cells where $K 2.10$ is expressed. Nevertheless, the major part of the follicle preparation consisted of hair cortex, as assessed microscopically (data not shown). Overlapping probes covering the $K 2.10$ promoter from $-350 \mathrm{bp}$ to the transcription start site (Fig. 3) were synthesised for EMSA and DNase I footprinting assays. While many DNAprotein interactions were detected throughout the promoter (data not shown), we focussed our initial investigations on parts of the promoter containing recognised sequence motifs.

Using a probe centred over the LEF-1 site, we observed a DNase I footprint over the sequence -193 to -152 which spans this motif (Fig. 4A). A 20 bp oligonucleotide probe (D) containing the LEF-1 site bound proteins from follicle nuclear extracts to form a doublet complex in EMSA (Fig. 4B). Specificity of this complex was demonstrated by the ability of

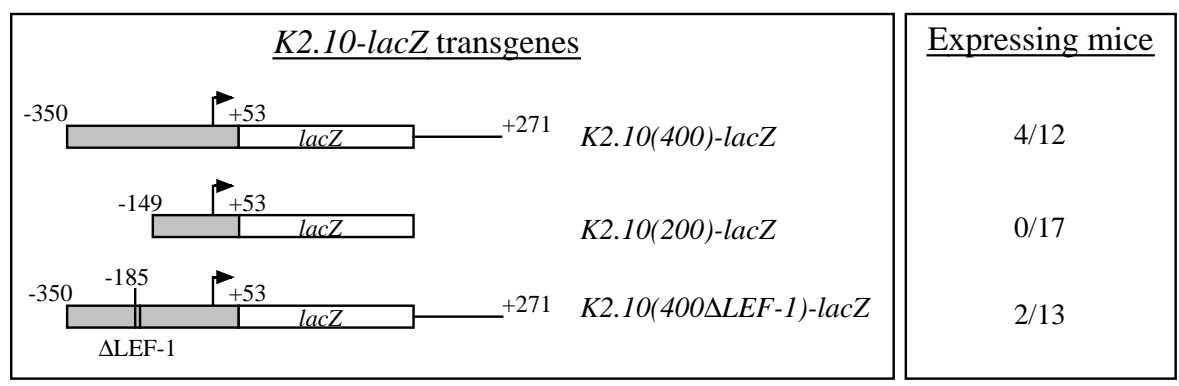

Fig. 1. Structure and expression of sheep K2.10-lacZ constructs in transgenic mice. The 3.85 $\mathrm{kb} l a c Z$ coding region was cloned at position +53 (bent arrows indicate the transcription initiation site at +1 ) in the $5^{\prime}$ untranslated region of $K 2.10$. The $K 2.10$ sequence +53 to +271 (part of the coding region of exon 1) was present at the $3^{\prime}$ end of the lac $Z$ insert in constructs $K 2.10(400)$-lacZ and $K 2.10(400 \Delta L E F-1)$-lacZ. The $K 2.10$ promoter sequences are stippled and the $5^{\prime}$ ends are shown at -350 or -149 . The LEF- 1 site at -185 , mutated in $K 2.10(400 \Delta L E F-1)$-lacZ, is boxed and labelled $\Delta \mathrm{LEF}-1$. Diagram not drawn to scale. The number of transgenic mice which express $\beta$-galactosidase is shown as a fraction of the total number of transgenic mice for each construct. 
a 100-fold molar excess of unlabelled oligonucleotide D, but not a non-specific sequence, to compete for binding to the probe. There was no detectable binding to the oligonucleotide $\triangle \mathrm{LEF}-1$ which carried the same mutated bases as used in the K2.10(400 LLEF-1)-lacZ transgene (Fig. 4B; see Materials and Methods). Evidence for involvement of LEF-1 in the complex binding oligonucleotide D was obtained by showing that LEF1 antiserum ablated binding of the slower migrating component of the complex, but antibodies to $\mathrm{CTF} / \mathrm{NF} 1$ transcription factors or an equivalent amount of non-specific protein (BSA) had no effect on complex formation (Fig. 4B). The unidentified, faster migrating component, while specific for

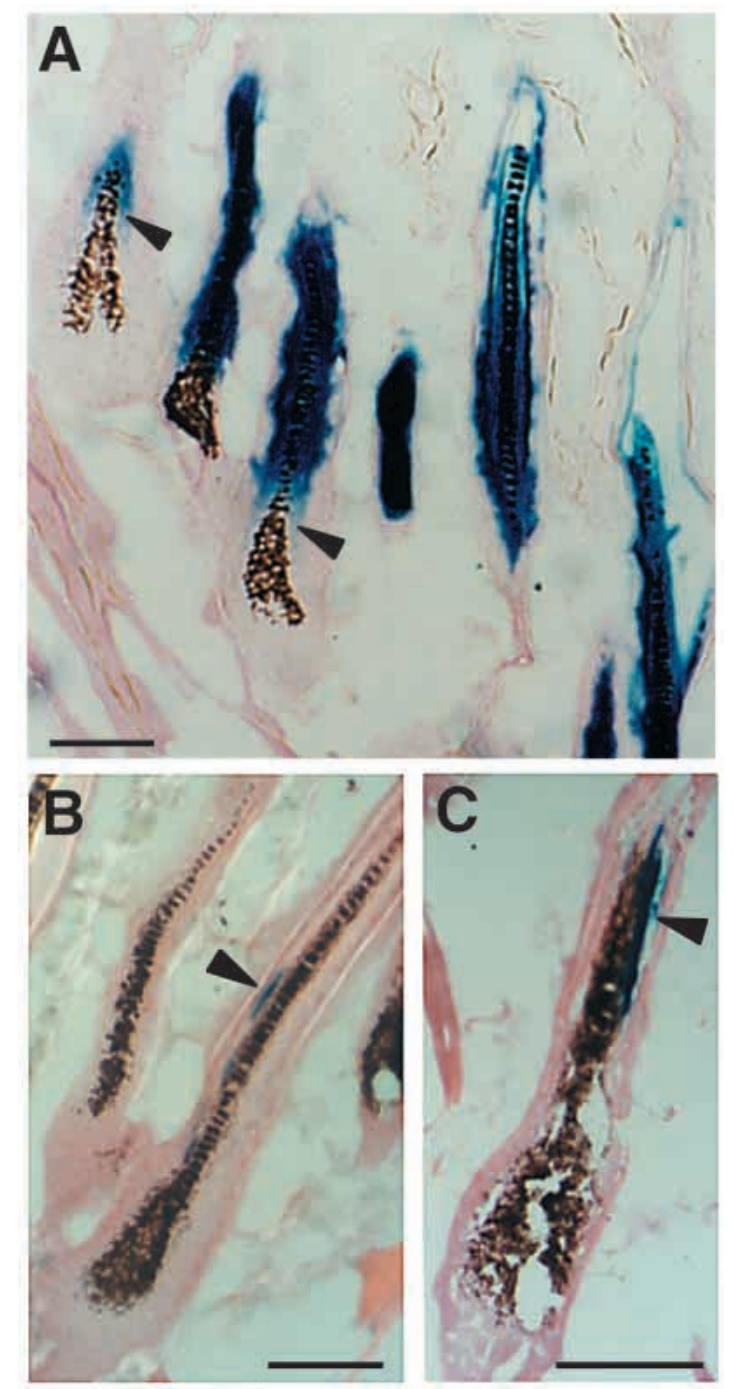

Fig. 2. Expression of $K 2 \cdot 10-l a c Z$ constructs in the skin of transgenic mice. (A) Skin from a $K 2.10(400)$-lac $Z$ transgenic mouse. Specific $\beta$ galactosidase activity (blue staining) is localised to the cortex of the hair follicle, as seen in the follicles where the bulb and lower shaft are visible and the $K 2.10$ promoter activity has just commenced (arrowheads). Staining beyond the cortex further along the shaft is due to diffusion of the reaction product. $(\mathrm{B}, \mathrm{C})$ Examples of patchy expression of $\beta$-galactosidase in the follicle cortex (arrowheads) in skin from two independent $K 2.10(400 \Delta L E F-1)$-lacZ transgenic mice. No expression is observed in the epidermis for either construct. Bars, $100 \mu \mathrm{m}$. probe $\mathrm{D}$, did not appear to interact with the antiserum as it was neither reduced in intensity nor supershifted. Interestingly, this component was competed by oligonucleotide E (Fig. 4B).

Several nucleotides downstream of the LEF-1 binding site is the sequence 5'-GCCTGAGGC-3' which resembles an AP2 binding site (Williams et al., 1988). Oligonucleotide E which spans this site bound a protein(s) from follicle nuclear extracts to form a complex of low mobility which was competed by unlabelled 'self' oligonucleotide and an AP2 consensus oligonucleotide but not by oligonucleotide D or a non-specific competitor (Fig. 4C). Probe E also formed a second specific complex, which was not competed by the consensus AP2 binding site but was weakly competed for by oligonucleotide D (Fig. 4C).

The DNase I footprint produced by follicle nuclear extract which spanned the LEF-1 binding site also encompassed the putative AP2 binding site in K2.10. In addition, recombinant AP2 protein produced a specific footprint over this AP2 motif ( -183 to -152 ; Fig. 4A). The footprinted sequences spanning the LEF-1 and AP2 sites all lie outside the promoter fragment used in the K2.10(200)-lacZ construct which had no activity in transgenic mice.

\section{Multiple sites upstream of the LEF-1 site bind Sp1}

Follicle nuclear extracts produced DNase I footprints at -343 to -318 and at -216 to -206 of the 400 bp $K 2.10$ promoter (data not shown). We identified two sequences overlapping these footprinted regions which matched the consensus binding site for Sp1 (Fig. 5A; Wu et al., 1994). These potential Sp1 binding sites were tested for binding of proteins by EMSA. Binding to probes $\mathrm{A}$ and $\mathrm{C}$ resulted in two retarded bands which were competed with a 100-fold molar excess of an Sp1 consensus oligonucleotide, indicating involvement of the Sp1 transcription factor (Fig. 5B). Further evidence of Sp1 binding to oligonucleotides $\mathrm{A}$ and $\mathrm{C}$ was obtained when a supershifted complex was produced by Sp1 antibody. The uppermost 'Sp1' band for both probes was the most affected by the Sp1 antiserum. A control antiserum, directed to CTF/NF1 proteins, produced a weak supershift of a complex binding to probe $\mathrm{A}$ but not probe $\mathrm{C}$ (Fig. 5B). Probes $\mathrm{A}$ and $\mathrm{C}$ also bound several other proteins, unique to each probe. For both probes, there were at least four bands which competed specifically with the unlabelled probe oligonucleotide but not with the Sp1 consensus sequence. None of these complexes has been identified as yet.

Another Sp1 consensus sequence is located upstream at 240 to -231 (Figs 3, 5A). For reasons unknown, DNase I footprinting assays did not give reproducible results over this region. However, oligonucleotide probe $\mathrm{B}$ that spans this sequence produced two major $(a$ and $b$ ) and two minor complexes (labelled Sp1; Fig. 5C). An Sp1 consensus oligonucleotide specifically competed for the two minor complexes. To substantiate the Sp1 interaction, when the bases GGA in the Sp1-like motif of oligonucleotide B were mutated to TAC (the two Gs are invariant in the Sp1 consensus; see Fig. 5A) there was a specific loss of both minor bands (Fig. 5C). The identity of the two major complexes ( $a$ and $b$ ) which were competed by unlabelled oligonucleotide B but not by the Sp1 consensus oligonucleotide is not known.

An interesting result was obtained when the overlapping oligonucleotide $\mathrm{C}$ was used as an unlabelled competitor for 


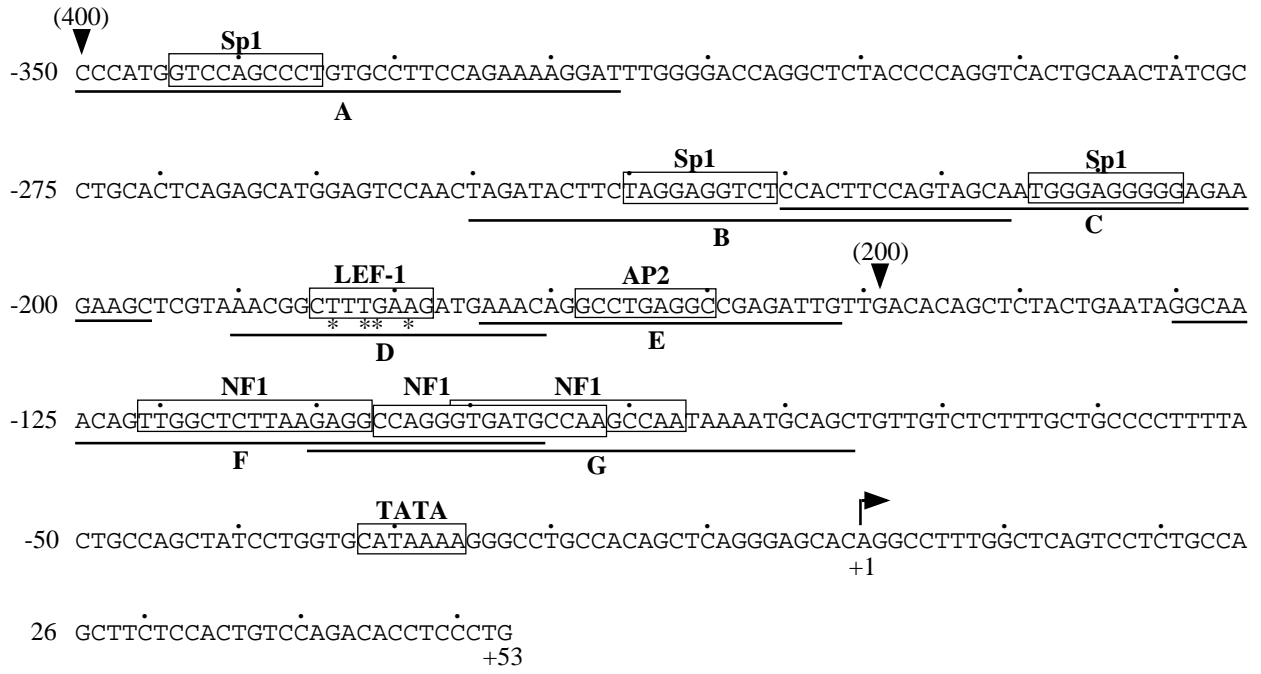

Fig. 3. Nucleotide sequence of the $5^{\prime}$ proximal domain of the sheep $K 2.10$ gene from -350 to +53 in the $5^{\prime}$ untranslated region. The arrowheads indicate the $5^{\prime}$ ends of the $K 2.10(400)$ and $K 2.10(200)$ promoter deletions shown in Fig. 1. The bent arrow at +1 denotes the transcription initiation site. Sequences of oligonucleotides A-G used in EMSA are underlined. The four bases mutated in the oligonucleotide D sequence to make the oligonucleotide $\Delta$ LEF-1 (see Materials and Methods) are indicated by asterisks. Putative transcription factor binding sites and a TATA motif are boxed. proteins binding probe $\mathrm{B}$, in which a complex running as a smear on the gel was noted in place of the Sp1-like complex (Fig. 5C). The same effect was not seen using the Sp1 consensus oligonucleotide as a competitor. This is suggestive of a specific association between proteins binding to probe $\mathrm{B}$ and proteins binding to oligonucleotide $\mathrm{C}$.

\section{Interaction of NF1-like factors with the proximal region of the $K 2.10$ promoter}

Three potential binding sites for NF1 transcription factors were detected in the proximal region of the $K 2.10$ promoter between -121 and -87 . Each of these sequences (boxed in Fig. 3) matched only one half of the palindromic NF1 consensus binding site (5'-TTGGC(N) $)_{5}$ GCCAA-3'; Chaudhry et al., 1997), but such 'half-sites' have been shown to bind NF1, albeit with low affinity (O'Connor and Bernard, 1995). Sequences overlapping the NF1 motifs at -125 to -109 and -105 to -87 were protected from digestion in the DNase I footprinting assay using follicle nuclear proteins (Fig. 6A). Oligonucleotides $F$ and $G$, which span these footprinted sequences, were used as probes in EMSA and a major complex formed using either probe (Fig. 6B). This complex contained a protein(s) antigenically related to NF1 as it was supershifted by NF1 antiserum. The consensus NF1 oligonucleotide also competed efficiently for the complex bound to probe $\mathrm{G}$ (Fig. $6 \mathrm{~B}$, lane 10) and probe $\mathrm{F}$ (data not shown). Oligonucleotide $\mathrm{F}$ appeared to have a lower affinity for the NF1-like protein(s) than probe $\mathrm{G}$ did, as indicated by competition experiments (Fig. 6B, lanes 8 and 9).

\section{DISCUSSION}

\section{Expression of K2.10-lacZ transgene constructs}

Transgenic mice carrying either a $14.5 \mathrm{~kb}$ sheep $K 2.10$ transgene or a fusion gene containing $2.8 \mathrm{~kb}$ of $5^{\prime}$ promoter sequence express transgene activity in the mouse hair follicle cortex according to the pattern of the endogenous gene in sheep (Powell and Rogers, 1990; Keough et al., 1995). In the present study, shortening the promoter to $400 \mathrm{bp}$ of $5^{\prime}$ proximal sequence produced a similar expression pattern where $\beta$ - galactosidase expression was confined to the follicle cortex of transgenic mice. Thus, as little as $400 \mathrm{bp}$ of $K 2.10$ promoter sequence contains the regulatory elements required for $K 2.10$ expression in the follicle cortex. However, when the promoter was further deleted to $200 \mathrm{bp}$ no expression was detectable in transgenic mice.

The lack of expression from the K2.10(200)-lacZ transgene could be explained by a number of possibilities. Although the $\mathrm{X}$-gal staining procedure is very sensitive, there is a threshold of enzyme concentration below which no blue staining is seen (Fire, 1992). Very low levels of expression from the minimal promoter may therefore go undetected. A second possibility is the presence of a negative regulatory element within this region of the promoter whose potential effects in the complete promoter may be over-ridden by upstream enhancers. NF1 proteins have been shown to act as repressors of some promoters where they bind to negative regulatory elements (Roy et al., 1992; Adams et al., 1995; Jahroudi et al., 1996), and we have demonstrated binding of NF1-like proteins to sequences within the $200 \mathrm{bp}$ promoter. It should also be noted that the $K 2.10$ (200)-lac $Z$ construct lacks $200 \mathrm{bp}$ of $K 2.10$ exon 1 sequence that was present in all other $K 2.10$ transgenes. Sequence analysis of this region reveals the presence of possible AP2 and Sp1 binding sites (data not shown). However, it is not known whether these motifs are functionally significant or simply reflect the GC-rich nature of the sequence which is typical of eukaryotic gene coding regions.

Reduction of the $K 2.10$ promoter from $2.8 \mathrm{~kb}$ to $400 \mathrm{bp}$ resulted in progressively fewer expressing transgenic mice. The large $K 2.10$ transgene ( $14.5 \mathrm{~kb}$ with $2.8 \mathrm{~kb}$ of $5^{\prime}$ promoter; Powell and Rogers, 1990) was active in virtually all transgenic mice albeit not in a copy-dependent manner (B. Powell, unpublished data). Similarly, in the production of keratin transgenic sheep, the larger $K 2.10$ promoter was active in most transgenic sheep (Bawden et al., 1998). It should be noted, though, that the $14.5 \mathrm{~kb}$ transgene and the transgenes used in sheep also contained $5 \mathrm{~kb}$ of $3^{\prime}$ flanking sequence from the $K 2.10$ gene, which may also help regulate expression. The $K 2.10-T A g$ construct with $2.8 \mathrm{~kb}$ of $K 2.10$ promoter was active in ten out of twenty transgenic mice (Keough et al., 1995), whilst $K 2.10(400)$-lac $Z$ was expressed in only four of twelve 
A

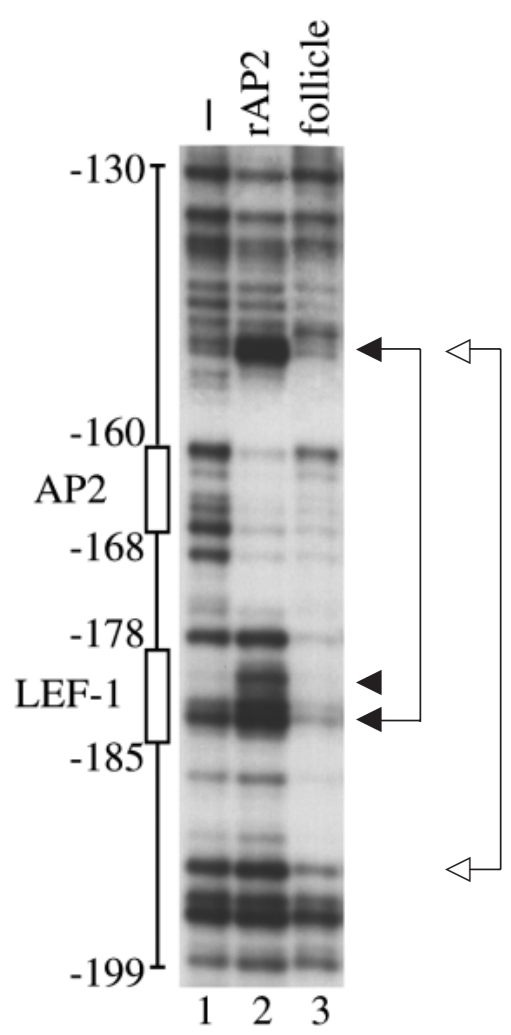

B
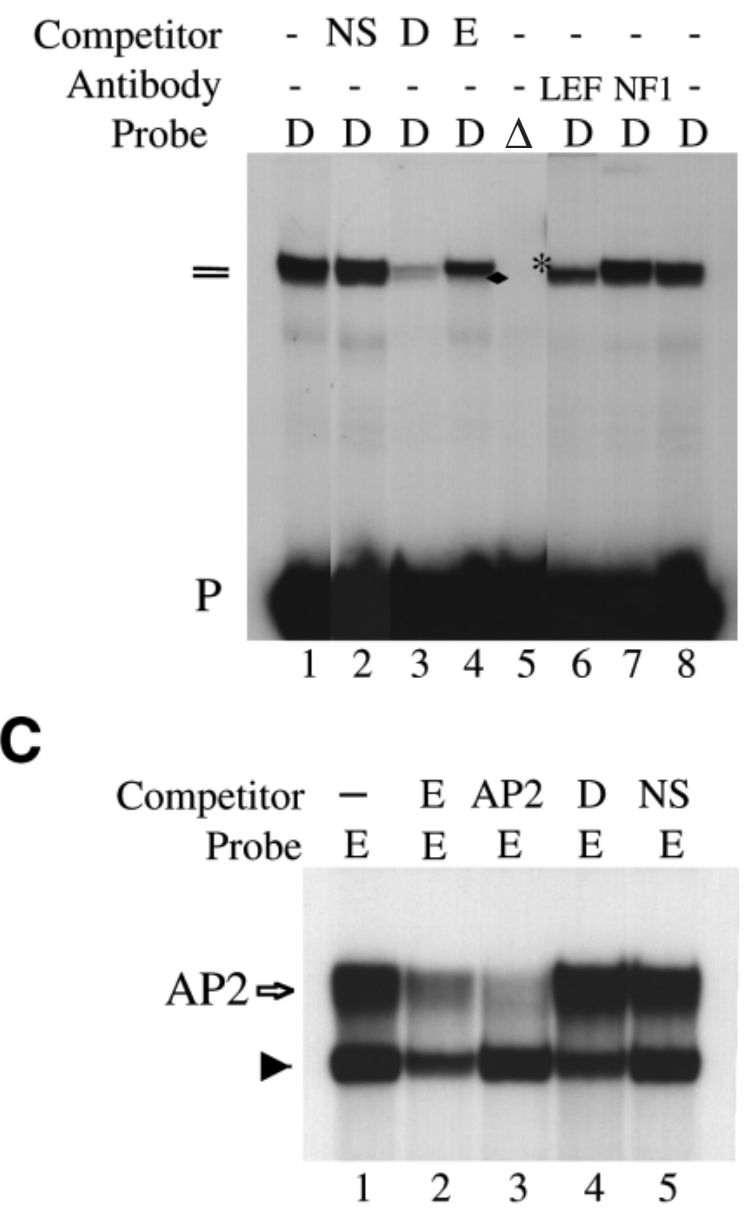

mice. The reduction in the percentage of transgenic mice expressing K2.10-lac $Z$ as the promoter fragment was shortened may indicate that shorter promoters are more susceptible to 'position effects' in the genome, possibly due to the loss of isolating elements such as matrix attachment or locus control regions (Phi-Van et al., 1990; Dillon and Grosveld, 1993) or distal enhancer elements (Walters et al., 1996).

\section{Mutation of the LEF-1 binding site reduces $K 2.10$ transgene activity}

The transcription factor LEF-1 is understood to play an architectural role in some $\mathrm{T}$ cell enhancers by inducing a sharp bend in the DNA upon binding (Grosschedl et al., 1994). This is thought to bring together factors binding to other sites in the promoter to form a higher-order nucleoprotein complex which activates transcription.

We tested the function of the LEF-1 sequence in the $400 \mathrm{bp}$ $K 2.10$ promoter by mutating it such that LEF- 1 could no longer bind. In the K2.10(400 $L E E F-1)-l a c Z$ transgenic mice, transgene expression in the hair follicle cortex was preserved but the expression level was significantly reduced. Therefore, it appears unlikely that LEF-1 is responsible for the folliclespecificity of $K 2.10$ expression, but it may augment transcription levels.

The reduction in $K 2.10$ promoter activity in $K 2.10(400 \Delta L E F-1)$-lac $Z$ transgenic mice is, to our knowledge, the first evidence which directly shows that the LEF-1 binding site is functionally significant in the transcriptional regulation of a hair keratin gene. As Zhou et al. (1995) suggested, LEF1 expression in the hair follicle may play a role in facilitating expression of a large set of hair keratin genes. This is strengthened by the presence of LEF-1 sites in the proximal promoters of 13 hair keratin promoters and by the localisation of expression of LEF-1 in the follicle bulb region where cortical cells originate.

Fig. 4. LEF-1 and AP2-like factors bind the sheep $K 2.10$ promoter. (A) DNase I footprint analysis of a $155 \mathrm{bp} \mathrm{K2.10}$ promoter fragment ( -199 to -130 shown here). The fragment was ${ }^{32} \mathrm{P}$-end-labelled on the upper strand and incubated with no protein (lane 1), $30 \mathrm{ng}$ of recombinant human AP2 (lane 2) or $50 \mu \mathrm{g}$ of crude follicle nuclear extract (lane 3). Positions of the consensus LEF-1 and AP2 sites are indicated diagrammatically. Filled arrows and arrowhead show footprint boundaries and hypersensitive sites for AP2; open arrows show footprint boundaries for follicle nuclear extract. (B) EMSA analysis of complexes formed with follicle nuclear extract and ${ }^{32} \mathrm{P}$ labelled, double-stranded oligonucleotides. Probe $\Delta \mathrm{LEF}-1(\Delta)$ was used in lane 5 and no binding was detected. Probe D (encompassing the LEF-1 site) was used in lanes 1-4, 6-8. The doublet complex formed is indicated by dashes. Competitor oligonucleotides at 100fold molar excess are: lane 1, none; lane 2, non-specific (NS); lane 3, oligo D; lane 4, oligo E. The lower band is competed specifically with oligo $\mathrm{E}$ (diamond). Reactions incubated in the presence of antibodies are shown in lane 6 (LEF-1 antiserum; asterisk denotes loss of band) and lane 7 (CTF/NF1 antiserum) and lane 8 contained BSA protein. Unbound probe, P. (C) EMSA analysis of follicle nuclear extract interacting with probe E encompassing the AP2 site (free probe is not shown). The uppermost complex (competed with AP2 oligo: lane 3) is labelled AP2 and the lower complex is marked by an arrowhead. Lane 1, no competitor; lanes 2-5 contain 100-fold molar excess of competitor as follows: lane 2, oligo E; lane 3, AP2 consensus oligo; lane 4, oligo D; lane 5, non-specific. 


\section{Analysis of LEF-1 and other factor binding sites in the K2.10(400) promoter}

When the LEF- 1 site in the $K 2.10$ promoter was analysed by EMSA a doublet complex was noted. One band appeared to be the result of LEF-1 binding as it was blocked by LEF-1-specific antibodies. The faster migrating band was not recognised by LEF-1 antibodies and possibly contained degraded protein or a LEF-1 variant, which shared binding site specificity but not identical antigenic determinants. Hence, while we have shown that the LEF-1 binding element is functionally important in the $K 2.10400$ bp promoter we cannot discriminate between the contribution of LEF-1 and the other protein.

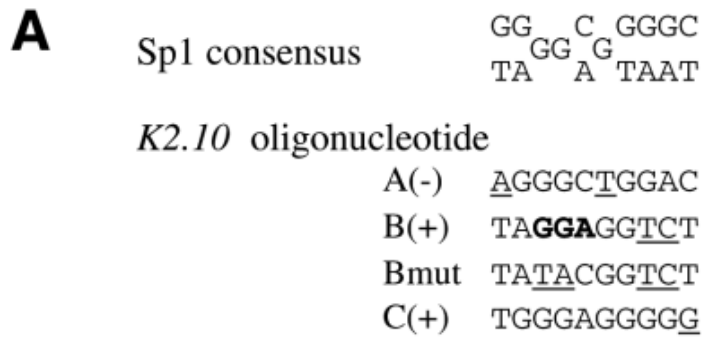

B
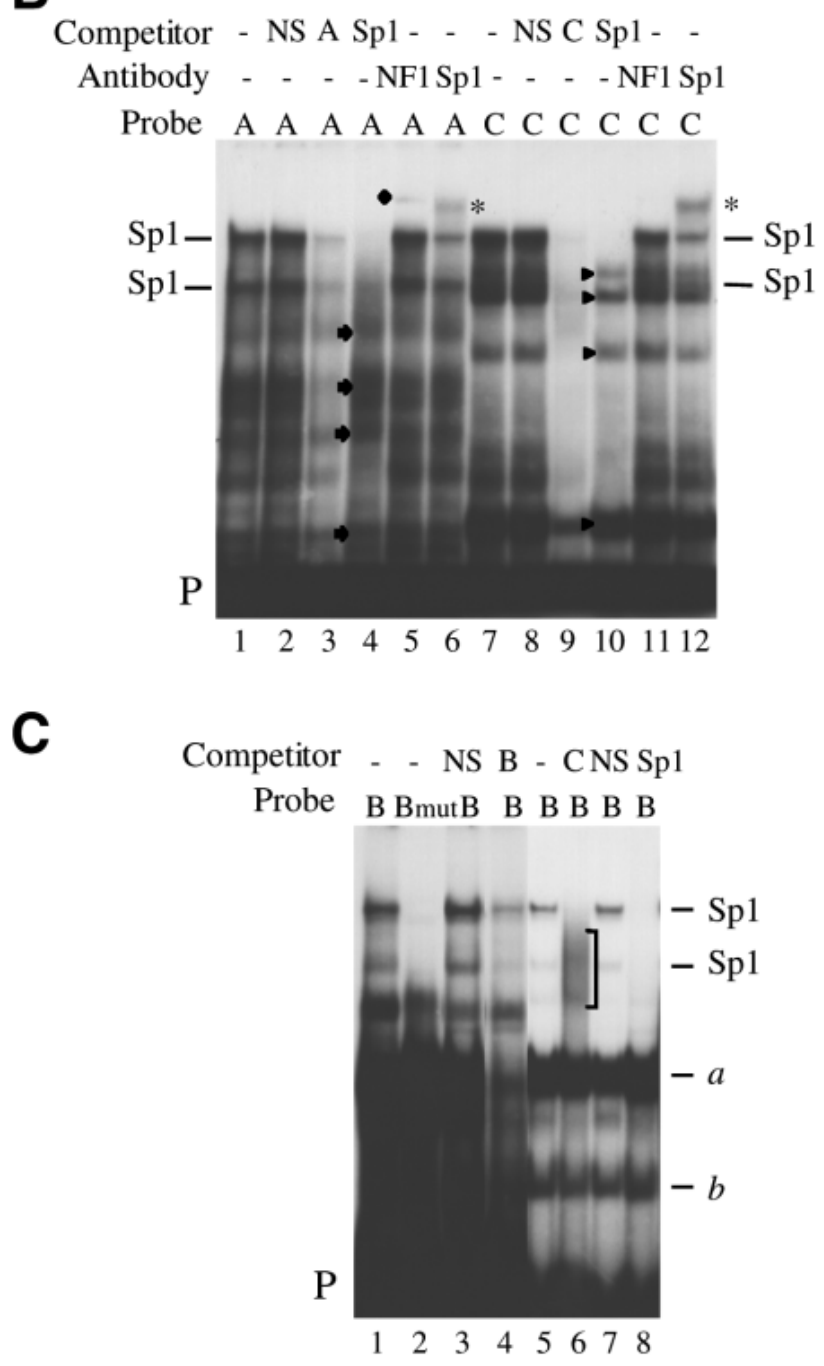

Studies on the TCR- $\alpha$ and HIV-1 enhancers have shown that LEF-1 alone cannot activate transcription and that interaction with other transcription factors bound to flanking sites in the enhancer is required (Giese and Grosschedl, 1993; Sheridan et al., 1995; Giese et al., 1995). We have tested follicle nuclear extracts for other proteins that bind sequences flanking the LEF-1 motif in the K2.10 400 bp promoter and which, by analogy, may be part of an activation complex involving LEF1. A potential AP2 binding site downstream of the LEF-1 motif was shown to bind protein by EMSA and DNase I footprint analysis. It is not surprising that AP2 might regulate hair keratin genes as functional AP2 binding sites are found in several epidermal keratin IF promoters (Leask et al., 1991; Ohtsuki et al., 1993; Eckert et al., 1997). The EMSA probe spanning the $K 2.10$ AP2 binding site also formed a complex involving protein(s) distinct from AP2. There may be similarity between the proteins in this second complex and the LEF-1 binding site complex as indicated by cross-competitions in EMSA. Notably, the unidentified AP2 site complex was reduced in the presence of the LEF-1 oligonucleotide while the AP2 site oligonucleotide competed for the faster migrating band formed by the LEF-1 probe.

Three distinct regions of the $K 2.10400 \mathrm{bp}$ promoter upstream of the LEF-1 site bound a complex which, by several lines of evidence, was likely to include the transcription factor Sp1. Sp1 may be a major contributor to the level of expression achieved by the $K 2.10400$ bp promoter, even though the individual sites do not appear to be high affinity sites for $\mathrm{Sp} 1$, because interactions between multiple Sp1 factors bound at different DNA sites can result in synergistic effects (Pascal and Tjian, 1991; Persengiev et al., 1995). The novel complex

Fig. 5. Characterisation of $\mathrm{Sp} 1$ binding sites in the $K 2.10$ promoter. (A) Sequence comparisons of the $\mathrm{Sp} 1$ consensus binding site (Wu et al., 1994) and three sequences in the $K 2.10$ promoter, identified by the oligonucleotide in which they are located (see Fig. 3). The (-) and $(+)$ indicate lower and upper strand sequences, respectively. Bases underlined differ from the $\mathrm{Sp} 1$ consensus. The bases GGA in bold-type in sequence $\mathrm{B}$ are mutated to TAC in the oligonucleotide B-mut. (B) EMSA analysis using oligonucleotides A (lanes 1-6) and $\mathrm{C}$ (lanes 7-12) as probes. Reactions shown in lanes 1 and 7 contained no competitors. Competitor oligonucleotides used at 100-fold molar excess over probe are: lanes 2 and 8, non-specific; lane 3, oligo A; lane 9, oligo C; lanes 4 and 10, Sp1 consensus oligo. The bands labelled Sp1 are specifically competed for by the Sp1 consensus oligonucleotide. The complexes marked by arrows bind specifically to probe $\mathrm{A}$ and those marked by arrowheads bind specifically to probe $\mathrm{C}$, as they are competed by 'self' oligonucleotide but not by non-specific or Sp1 consensus oligonucleotides. Antiserum to $\mathrm{CTF} / \mathrm{NF} 1$ proteins was included in reactions shown in lanes 5 and 11 , and a weak supershift in lane 5 is indicated (diamond). Reactions incubated in the presence of Sp1 antibodies are shown in lanes 6 and 12 and supershifts are denoted by asterisks. (C) EMSAs performed with oligonucleotide B (lanes 1, 3-8) and B-mut (lane 2) as probes. Lanes 1-4 are over-exposed to highlight the 'Sp1' complexes. All marked complexes are competed by excess unlabelled oligonucleotide B (lane 4) but not by a non-specific oligonucleotide (lanes 3 and 7) (unmarked complexes in lanes 1-4 are non-specific). Lanes 1, 2 and 5 contain no competitor. Lane 8 shows competition of the two slowest migrating bands by the $\mathrm{Sp} 1$ consensus oligonucleotide. Addition of competitor oligonucleotide C (lane 6) results in a novel complex migrating ahead of the 'Sp1' bands as a smear (bracket). Unbound probe, $\mathrm{P}$. 


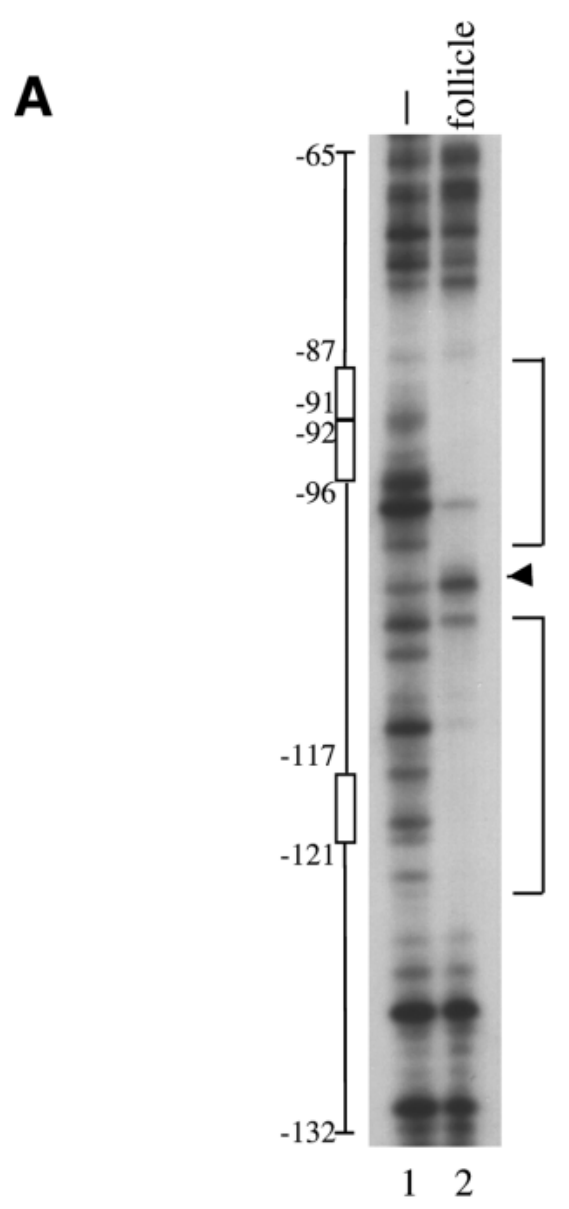

B

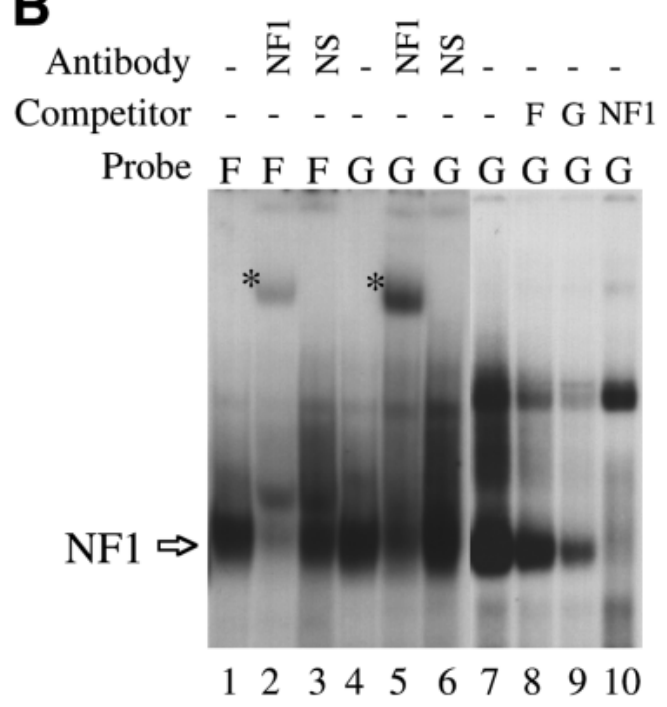

produced when one Sp1 site (oligonucleotide C) was added as a competitor for binding of proteins to another (probe B) may be due to interactions between $\mathrm{Sp} 1$ (or other) proteins bound to both oligonucleotides. In addition to $\mathrm{Sp} 1$, we detected several other proteins binding to all three probes containing $\mathrm{Sp} 1$ sites. The same complexes were not formed with each probe, reflecting the different sequences flanking the Sp1 core motifs. These complexes are yet to be identified, although an
Fig. 6. $K 2.10$ sequences containing multiple NF1 binding sites are bound by follicle nuclear proteins. (A) DNase I footprinting performed on a 155 bp $K 2.10$ promoter fragment ( -132 to -65 shown here) ${ }^{32} \mathrm{P}$-end-labelled on the upper strand. The positions of three NF1 half-sites (5'-TTGGC-3') are boxed at the left of the figure. The probe was incubated with no protein (lane 1) or $50 \mu \mathrm{g}$ of follicle nuclear extract (lane 2). Protected regions are bracketed and a DNase I hypersensitive site is indicated by an arrowhead. (B) EMSA analysis of proteins interacting with oligonucleotide probes $F$ (lanes 1-3) and G (lanes 4-10) (free probe is not shown). The major complex is marked as NF1. Unmarked bands are non-specific. Antiserum to $\mathrm{CTF} / \mathrm{NF} 1$ proteins was included in reactions shown in lanes 2 and 5 and a supershifted complex (asterisk) is seen for each probe, accompanied by a decrease in the NF1 complex. Lanes 3 and 6 show reactions incubated in the presence of a control antiserum (NS). For lanes 7-10, competitor oligonucleotides were added as follows: lane 7, none; lane 8, oligo F; lane 9, oligo G; lane 10, NF1 consensus oligonucleotide.

NF1-like protein may bind near the upstream Sp1 site (probe A) given some evidence of a supershifted complex with an antiserum to $\mathrm{CTF} / \mathrm{NF} 1$ proteins.

Like the LEF-1 and AP2 sites, the sequences which bound $\mathrm{Sp} 1$ are in the distal part of the $K 2.10400$ bp promoter, which was required for promoter activity in transgenic mice. In the shorter $200 \mathrm{bp}$ promoter, which contains a TATA box and the transcription initiation site, we also discovered binding sites for NF1-like proteins. As for Sp1 and AP2 transcription factors, NF1-like factors have a widespread distribution and expression of all four known isoforms of NF1 has been noted in mouse whisker follicles (Chaudhry et al., 1997). While the $200 \mathrm{bp}$ promoter did not have any detectable activity in transgenic mice, the NF1 sites may nevertheless be functional in the context of the $400 \mathrm{bp}$ promoter where proteins binding both the proximal and distal regions of the promoter might act synergistically on the basal transcription unit. Alternatively, it is possible that NF1-like factors act in a negative way on the basal K2.10 promoter, suppressing expression in the proliferating follicle bulb cells, for example, or in other noncortical cells. Cell-type-specific gene regulation involving an NF1-like repressor has previously been reported for the rat growth hormone promoter in nonpituitary cells (Roy et al., 1992).

The transcription factors so far identified in this and other studies of keratin gene expression (AP1, AP2, NF1 and Sp1) are largely ones that are shared in the control of many other genes. LEF-1, with its binding site positioned centrally in the $K 2.10$ minimal promoter and with its DNA bending properties, may act as an enhancer of $K 2.10$ expression by bringing together such factors into an active complex. Other binding proteins discovered in this study may also be involved in defining tissue- and differentiation-specificity of hair keratin gene expression. The data presented here define a minimal, functional hair keratin promoter and provide a preliminary characterisation of transcription factors which may be involved in expression of the intermediate filament gene, K2.10, and most likely other hair keratin genes.

We thank Dr R. Seamark and staff of the Department of Obstetrics and Gynaecology (University of Adelaide) for the use of microinjection facilities and for their assistance. This work was funded by the International Wool Secretariat and the Cooperative 
Research Centre for Premium Quality Wool. R.A.K. was supported by a postgraduate scholarship from the IWS.

\section{REFERENCES}

Adams, A. D., Choate, D. M. and Thompson, M. A. (1995). NF1-L is the DNA-binding component of the protein complex at the peripherin negative regulatory element. J. Biol. Chem. 270, 6975-6983.

Bawden, C. S., Powell, B. C., Walker, S. K. and Rogers, G. E. (1998). Expression of a wool intermediate filament keratin transgene in sheep alters fibre structure. Transgenic Research 7, 1-15.

Briggs, M. R., Kadonaga, J. T., Bell, S. P. and Tjian, R. (1986). Purification and biochemical characterization of the promoter-specific transcription factor, Sp1. Science 234, 47-52.

Chaudhry, A. Z., Lyons, G. E. and Gronostajski, R. M. (1997). Expression patterns of the four nuclear factor 1 genes during mouse embryogenesis indicate a potential role in development. Dev. Dynam. 208, 313-325.

Dillon, N. and Grosveld, F. (1993). Transcriptional regulation of multigene loci: multilevel control. Trends Genet. 9, 134-137.

Eckert R. L., Crish, J. F., Banks, E. B. and Welter, J. F. (1997). The epidermis: genes on - genes off. J. Invest. Dermatol. 109, 501-509.

Fire, A. (1992). Histochemical techniques for locating Escherichia coli $\beta$ galactosidase activity in transgenic organisms. Genet. Anal. Tech. Appl. 9, 151-158.

Giese, K. and Grosschedl, R. (1993). LEF-1 contains an activation domain that stimulates transcription only in a specific context of factor-binding sites. EMBO J. 12, 4667-4676.

Giese, K., Kingsley, C., Kirshner, J. R. and Grosschedl, R. (1995). Assembly and function of a TCR $\alpha$ enhancer complex is dependent on LEF1 -induced DNA bending and multiple protein-protein interactions. Genes Dev. 9, 995-1008.

Gottschalk, L. R. and Leiden, J. M. (1990). Identification and functional characterization of the human T-cell receptor $\beta$ gene transcriptional enhancer: common nuclear proteins interact with the transcriptional regulatory elements of the T-cell receptor $\alpha$ and $\beta$ genes. Mol. Cell. Biol. 10, 5486-5495.

Grosschedl, R., Giese, K. and Pagel, J. (1994). HMG domain proteins: Architectural elements in the assembly of nucleoprotein structures. Trends Genet. 10, 94-100.

Haynes, T. L., Thomas, M. B., Dusing, M. R., Valerius, M. T., Potter, S. S. and Wiginton, D. A. (1996). An enhancer LEF-1/TCF-1 site is essential for insertion site-independent transgene expression in thymus. Nucl. Acids Res. 24, 5034-5044.

Hogan, B., Costantini, F. and Lacy, E. (1986). Manipulating the Mouse Embryo: a Laboratory Manual. Cold Spring Harbor Laboratory Press, Cold Spring Harbor, New York.

Jahroudi, N., Ardekani, A. M. and Greenberger, J. S. (1996). An NF1-like protein functions as a repressor of the von Willebrand factor promoter. $J$. Biol. Chem. 271, 21413-21421.

Jerkins, A. A., Liu, W. R., Lee, S. and Sul, H. S. (1995). Characterization of the murine mitochondrial glycerol-3-phosphate acyltransferase promoter J. Biol. Chem. 270, 1416-1421.

Kaytes, P., McNab, A. R., Rea, T. J., Groppi, V., Kawabe, T. T., Buhl, A. E., Bertolino, A. P., Hatzenbuhler, N. T. and Vogeli, G. (1991). Hairspecific keratins: characterization and expression of a mouse type I keratin gene. J. Invest. Dermatol. 97, 835-842.

Keough, R. A., Powell, B. C. and Rogers, G. E. (1995). Targeted expression of SV-40 T antigen in the hair follicle of transgenic mice produces an aberrant phenotype. J. Cell Sci. 108, 957-966.

Kratochwil, K., Dull, M., Farinas, I., Galceran, J. and Grosschedl, R. (1996). Lef1 expression is activated by BMP-4 and regulates inductive tissue interactions in tooth and hair development. Genes Dev. 10, 1382-1394.

Leask, A., Byrne, C. and Fuchs, E. (1991). Transcription factor AP2 and its role in epidermal-specific gene expression. Proc. Nat. Acad. Sci. USA 88, 7948-7952.

Leegwater, P. A. J., van Driel, W. and van der Vliet, P. C. (1985), Recognition site of nuclear factor 1 , a sequence-specific DNA-binding protein from HeLa cells that stimulates adenovirus DNA replication. EMBO J. 4, 1515-1521.

McNab, A. R., Wood, L., Theriault, N., Gierman, T. and Vogeli, G. (1989). An ultra-high sulphur keratin gene is expressed specifically during hair growth. J. Invest. Dermatol. 92, 263-266.
McNab, A. R., Andrus, P., Wagner, T. E., Buhl, A. E., Waldon, D. J., Kawabe, T. T., Rea, T. J., Groppi, V. and Vogeli, G. (1990). Hair-specific expression of chloramphenicol acetyltransferase in transgenic mice under the control of an ultra-high-sulphur keratin promoter. Proc. Nat. Acad. Sci. USA 87, 6848-6852.

O'Connor, M. and Bernard, H.-U. (1995). Oct-1 activates the epithelialspecific enhancer of human papillomavirus type 16 via a synergistic interaction with NF1 at a conserved composite regulatory element. Virology 207, 77-88

Ohtsuki, M., Flanagan, S., Freedberg, I. M. and Blumenberg, M. (1993). A cluster of five nuclear proteins regulates keratin gene transcription. Gene Expression 3, 201-213.

Oosterwegel, M., van de Wetering, M., Timmerman, J., Kruisbeek, A., Destree, O., Meijlink, F. and Clevers, H. (1993). Differential expression of the HMG box factors TCF-1 and LEF-1 during murine embryogenesis. Development 118, 439-448.

Pascal, E. and Tjian, R. (1991). Different activation domains of Sp1 govern formation of multimers and mediate transcriptional synergism. Genes Dev. 5, 1646-1656.

Persengiev, S. P., Saffer, J. D. and Kilpatrick, D. L. (1995). An alternatively spliced form of the transcription factor Sp1 containing only a single glutamine-rich transactivation domain. Proc. Nat. Acad. Sci. USA 92, 91079111.

Phi-Van, L., von Kries, J. P., Osterag, W. and Stratling, W. H. (1990). The chicken lysozyme $5^{\prime}$ matrix attachment region increases transcription from a heterologous promoter in heterologous cells and dampens position effects on the expression of transfected genes. Mol. Cell. Biol. 10, 2302-2307.

Powell, B. C. and Rogers, G. E. (1990). Cyclic hair-loss and regrowth in transgenic mice overexpressing an intermediate filament gene. EMBO J.9, 1485-1493.

Powell, B. C., Nesci, A. and Rogers, G. E. (1991). Regulation of keratin gene expression in hair follicle differentiation. Ann. NY Acad. Sci. 642, 1-20.

Powell, B., Crocker, L. A. and Rogers, G. E. (1992). Hair follicle differentiation: expression, structure and evolutionary conservation of the hair type II keratin intermediate filament gene family. Development 114 417-434.

Powell, B. C. and Rogers, G. E. (1997). The role of keratin proteins and their genes in the growth, structure and properties of hair. In Formation and Structure of Human Hair (ed. P. Jolles, H. Zahn and H. Hocker), pp. 59148. Basel, Switzerland: Birkhauser Verlag.

Redondo, J. M., Hata, S., Brockelhurst, C. and Krangel, M.S. (1990). A T cell-specific transcriptional enhancer within the human $\mathrm{T}$ cell receptor delta locus. Science 247, 1225-1229.

Rogers, G. E., Martinet, N., Steinert, P., Wynn, P., Roop, D., Kilkenny, A., Morgan, D. and Yuspa, S. (1987). Cultivation of murine hair follicles as organoids in a collagen matrix. J. Invest. Dermatol. 89, 369-379.

Rogers, M. A., Winter, H., Langbein, L., Krieg, T. and Schweizer, J. (1996). Genomic characterization of the human type I cuticular hair keratin hHa2 and identification of an adjacent novel type I hair keratin gene hHa5. $J$. Invest. Dermatol. 107, 633-638.

Rogers, M. A., Langbein, L., Praetzel, S., Moll, I., Krieg, T., Winter, H. and Schweizer, J. (1997). Sequences and differential expression of three novel human type II hair keratins. Differentiation 61, 187-194.

Roy, R. J., Gosslin, P., Anzivino, M. J., Moore, D. D. and Guerin, S. L. (1992). Binding of a nuclear protein to the rat growth hormone silencer element. Nucl. Acids Res. 20, 401-408.

Sanes, J. R., Rubenstein, J. L. R. and Nicolas, J.-F. (1986). Use of a recombinant retrovirus to study post-implantation cell lineage in mouse embryos. EMBO J. 5, 3133-3142.

Sawada, S. and Littman, D. R. (1991). Identification and characterization of a T-cell-specific enhancer adjacent to the murine CD4 gene. Mol. Cell. Biol. 11, 5506-5515.

Schneider, R., Gander, I., Muller, V., Mertz, R. and Winnacker, E. L. (1986). A sensitive and rapid gel retention assay for nuclear factor I and other DNA-binding proteins in crude nuclear extracts. Nucl. Acids Res. 14, 1303-1317.

Sheridan, P. L., Sheline, C. T., Cannon, K., Voz, M. L., Pazin, M. J., Kadonaga, J. T. and Jones, K. A. (1995). Activation of the HIV-1 enhancer by the LEF-1 HMG protein on nucleosome-assembled DNA in vitro. Genes Dev. 9, 2090-2104.

Steinert, P. M. and Roop, D. R. (1988). Molecular and cellular biology of intermediate filaments. Annu. Rev. Biochem. 57, 593-625.

Tobiasch, E., Schweizer, J. and Winter, H. (1992). Structure and site of expression of a murine type II hair keratin. Mol. Biol. Rep. 16, 39-47. 
Travis, A., Amsterdam, A., Belanger, C. and Grosschedl, R. (1991). LEF1, a gene encoding a lymphoid-specific protein with an HMG domain, regulates T-cell receptor $\alpha$ enhancer function. Genes Dev. 5, 880-894.

van Genderen, C., Okamura, R. M., Farinas, I., Quo, R.-G., Parslow, T. G., Bruhn, L. and Grosschedl, R. (1994). Development of several organs that require inductive epithelial-mesenchymal interactions is impaired in LEF-1-deficient mice. Genes Dev. 8, 2691-2703.

Walters, M. C., Magis, W., Fiering, S., Eidemiller, J., Scalzo, D., Groudine, M. and Martin, D. I. K. (1996). Transcriptional enhancers act in cis to suppress position-effect variegation. Genes Dev. 10, 185-195.

Waterman, M. L., Fischer, W. H. and Jones, K. A. (1991). A thymus-specific member of the HMG protein family regulates the human $\mathrm{T}$ cell receptor $\mathrm{C} \alpha$ enhancer. Genes Dev. 5, 656-669.
Williams, T., Admon, A., Lüscher, B. and Tjian, R. (1988). Cloning and expression of AP-2, a cell-type-specific transcription factor that activates inducible enhancer elements. Genes Dev. 2, 1557-1569.

Winter, H., Siry, P., Tobiasch, E. and Schweizer, J. (1994). Sequence and expression of murine type I hair keratins $\mathrm{mHa} 2$ and mHa3. Exp. Cell Res. 212, 190-200.

Wu, R.-L., Chen, T.-T. and Sun, T.-T. (1994). Functional importance of an Sp1- and an NFkB-related nuclear protein in a keratinocytespecific promoter of rabbit K3 keratin gene. J. Biol. Chem. 269, 2845028459.

Zhou, P., Byrne, C., Jacobs, J. and Fuchs, E. (1995). Lymphoid enhancer factor 1 directs hair follicle patterning and epithelial cell fate. Genes Dev. 9, 570-583. 